\title{
Benefit Analysis and System Design Considerations for Drag Reduction of Inactive Hover Rotors on Electric Fixed-Wing VTOL Vehicles
}

\author{
Stahl, Philipp ${ }^{1}$, Rößler, Christian ${ }^{2}$, Hornung, Mirko ${ }^{3}$ \\ Technical University of Munich, Institute of Aircraft Design, Boltzmannstr. 15, Garching/München, 85748, \\ Germany
}

Fixed-wing VTOL aircraft are aerial vehicles capable of both hover and fast forward flight. Lift during take-off and landing is generated by rotors. After takeoff, they transition into forward flight mode in which a wing produces the lift. For the widespread fixed-wing VTOL configurations that use separate powertrains to produce vertical hover thrust and horizontal cruise thrust, the inactive hover rotor adds aerodynamic drag in cruise flight. This paper presents the systematic development, functional testing, drag reduction measurement and aircraft-level performance impact analysis of a drag reduction system for inactive hover rotors. With the key requirements identified, subfunction solutions were derived and combined to a consistent drag reduction system concept employing a morphological box approach. The main principle of the concept is the retraction of the two blade rotor into a recess in the fuselage using the bidirectional rotation of a threaded rotor shaft. The implementation of this concept proved robust operation in a wind tunnel. A significant drag reduction due to the retracted rotor compared to fixed, fuselage-aligned rotor could be assessed. With the gained data, a validation and modification of the inactive rotor drag modelling was possible. Furthermore, an extrapolation of the rotor storage mechanism's benefit on a typical fixed-wing VTOL aircraft's mission performance was conducted. An increase in cruise endurance between 1 and $6 \%$ over fuselage-aligned rotors is estimated for small unmanned aircraft, while manned urban air transport aircraft can realize improvements in the order of $10 \%$.

$\begin{array}{ll}\text { VTOL } & =\text { vertical take-off and landing } \\ \text { UAV } & =\text { unmanned aerial vehicle } \\ \text { CAD } & =\text { computer aided design } \\ \text { DC } & =\text { direct current } \\ \text { AC } & =\text { alternating current } \\ \text { ESC } & =\text { electronic speed controller } \\ \text { RPM } & =\text { revolutions per minute } \\ C_{D} & =\text { drag coefficient } \\ S & =\text { reference area } \\ D & =\text { drag force }\end{array}$

Nomenclature
\[ \begin{array}{ll}q & =\text { dynamic pressure } \\ t & =\text { time } \\ E & =\text { energy } \\ P & =\text { power } \\ v & =\text { airspeed } \\ \eta & =\text { powertrain efficiency } \\ m & =\text { mass } \\ L / D & =\text { glide ratio } \\ g & =\text { gravitational constant } \\ \varrho & =\text { air density }\end{array} \]

\section{Introduction}

$\mathrm{M}$ ultirotor and fixed wing UAV are already in use for tasks like aerial filming, surveillance, photogrammetric survey, etc. Multirotor offer the capability of take-off and landing in confined environments but cannot provide enough range and endurance for certain missions. Fixed-wing UAV offer the latter but require space and infrastructure for take-off and landing. Fixed-wing VTOL UAV try to close this gap. They can operate in a powered lift mode for take-off and landing and in a wing-borne forward flight mode.

For the same reasons, man-carrying fixed-wing VTOL aircraft are recently traded as one solution for future urban mobility $^{1}$. The use of electric powertrains enables VTOL from platforms inside the noise-sensitive urban environment. Efficient wing-borne flight allows for necessary ranges despite the high mass of the electric energy storage.

\footnotetext{
${ }^{1}$ Research Scientist, Technical University of Munich, Institute of Aircraft Design, philipp.stahl@tum.de

${ }^{2}$ Research Associate, Technical University of Munich, Institute of Aircraft Design, christian.roessler@tum.de

${ }^{3}$ Professor, Technical University of Munich, Institute of Aircraft Design, mirko.hornung@tum.de
} 


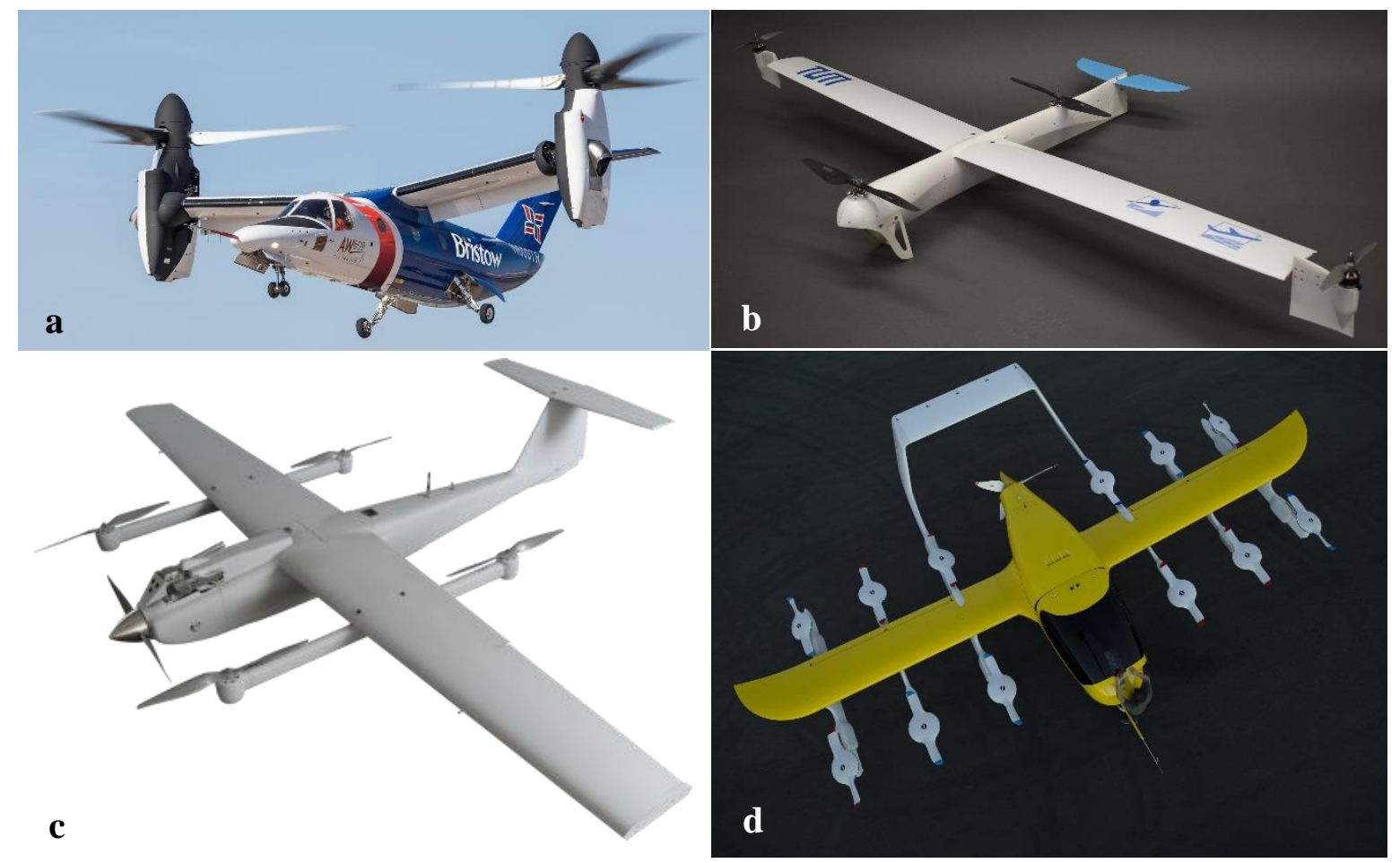

Figure 1: a) tilt rotor vehicle with dual use powertrain for hover and cruise $\odot$ Vertical Magazine

b) UAV with fuselage rotors exclusively for hover and dual use wingtip tilt rotors $\mathbb{O}$ TUM c/d) unmanned and manned vehicles with separate hover lift and cruise thrust powertrains, hover rotors in cruise position (A)Arcturus UAV, Kitty Hawk Cora

A fundamental property of a fixed-wing VTOL design is the grade of separation of hover lift powertrain and cruise thrust powertrain. Figure 1 shows representatives for different powertrain separation grades. a) depicts the one extreme: by tilting the rotor in vertical or horizontal position, hover lift and cruise thrust is generated by the same powertrain. c) and d) on the contrary use exclusive powertrains for the hover lift and cruise thrust tasks. b) settles between the two extremes. It solely tilts the small portion of cruise thrust vertically to contribute to the hover lift mainly provided by the fuselage mounted rotors. In first place, approach a) might appear as the obvious design choice due to the all-time active and therefore lightest powertrain. Tail-sitter concepts left out, dual use powertrain vehicles require a tilt of the rotor's thrust vector from vertical to horizontal. Dimensioned to actuate the rotating and high-thrust load of a VTOL rotor, the related tilt mechanisms add considerable mass to the aircraft. Their inherent complexity and wear are main drivers for development and maintenance cost. Furthermore, the single powertrain has to be designed for the two contrary operating points of hover and cruise. Thrust of more than half the aircraft weight (in case of Figure 1a) has to be provided at very low rotor inflow airspeeds. High diameter rotors with low pitch and low blade tip speed are able to provide hover lift thrust under low power consumption and noise emission. In cruise, the thrust force requirement is down to one fifth, but at very high rotor inflow airspeeds. Here, an efficient rotor design requires high pitch blades with limited diameter to not approach the speed of sound at the tips. The separated hover lift and cruise thrust design approach allows to apply these ideal rotor layouts to the respective powertrain and achieve maximum powertrain efficiencies. A single powertrain operating at the two concurrent conditions of hover and cruise will need to tolerate efficiency losses. The consequence is a higher power demand in typically both hover and cruise flight. This, in turn, leads to an increased engine size and further lowered, inefficient throttle settings in cruise, a heavier battery and an increased amount of waste heat and cooling effort. Performance-wise, fixed-wing VTOL design approach a) commends itself for missions with very short hover times. The advantage of the basically lighter powertrain is then not yet used up by the negative impact of the powertrain design tradeoff. From a redundancy and safety perspective, a failure in the dual use powertrain affects both hover and cruise functionality. Approach c)/d) is able to vertically land even in case of a cruise powertrain failure. Recently appearing electric fixed-wing VTOL designs clearly tend to a mostly or completely separated hover lift and cruise thrust separation. Their low complexity and low maintenance propulsion and actuation system, easy to implement redundancy at still competitive performance indicate the lower development and operating cost. 
A result of separated hover and cruise propulsion is that the vertical thrust rotors are inactive during wing-borne cruise flight and negatively affect the aerodynamic performance by their drag. In the context of the typically high design airspeed of fixed-wing VTOL aircraft and the need for low-power cruise to reach sufficient ranges with battery driven vehicles, the inactive rotor drag becomes a factor necessary to explicitly address within fixed-wing VTOL aircraft design. A range of approaches - from simply accepting the drag of inactive rotors to dedicated system to vanish the drag completely - is imaginable. Every approach however must have the overall performance benefit in mind - meaning that drag savings must not be used up by additional system mass or power consumption. Additionally, the system's impact on operation and safety must be regarded.

This paper describes the considerations during the development process of a storage system for inactive hover rotors. A functional prototype is used to establish and demonstrate the flight readiness of the system as well as to assess the actual drag savings in a wind tunnel experiment. The gained data allows for a conclusive evaluation of the system's impact on overall aircraft performance.

\section{Considerations for the Design of an Inactive Hover Rotor Drag Reduction System}

\section{A. System Requirements}

To start the development process, an informal list of requirements was compiled. It anticipates the operation in a flying fixed-wing VTOL aircraft and already includes the findings of functional testing. It as well gives a rationale for each requirement.

1) Sufficient Performance Benefit: The justification of any inactive hover rotor drag reduction approach is an enhancement in overall aircraft performance high enough to accept the cost and effort for its installation. The performance benefit can, like used in this paper, be quantified in the extension of cruise flight time or covered distance in comparison to a reference aircraft configuration. An obvious reference is, as it incorporates the easiest drag reduction approach, an aircraft with hover rotors aligned with the fuselages (see Figure 1c/d). From a technical viewpoint, the performance benefit originates from the reduction the vehicle's parasitic drag. The reduction or omission of the parasitic drag of the rotors and its shafts, but also a greater extent of laminar flow on the fuselages are the source therefore. The aerodynamic performance benefit is reduced by the system's mass that adds on the aircraft mass or - even worse - reduces battery mass if a maximum aircraft mass may not be exceeded. Furthermore, the system's power consumption, e.g. for an active rotor position hold, or an adverse influence on other systems, e.g. blocked rotor downwash by opened housing doors that reduces thrust, hamper the overall performance benefit. An analysis of these influences on overall performance benefit can be formulated for an aircraft configuration and is done in chapter IV.

2) Impact on Hover Thrust Generation: A failure within the inactive rotor drag reduction system may not prohibit the rotor's lift thrust generation. Due to the typically high stall speed and minimalistic landing gear design of fixed-wing VTOL, it is unlikely that suitable forward flight emergency landing sites, especially within an urban environment, are available. The vertical thrust generation therefore must be designed reliable and least possible periphery systems should be able to affect its functionality - e.g. rotor rotation should not be prohibited by a stuck housing door. A demonstration of the reliability of such periphery systems and the installation of redundant actuation might become necessary. Furthermore, the activation timespan between stored rotor state and rotor operative state must be reduced. The inactivation timespan is however less critical. In case of a system failure or stall speed shortfall during wing-borne mode, an independent vertical thrust generation system can be used as recovery flight mode. The faster the hover lift system is operative, the smaller is altitude loss or attitude deviation. The RPM envelope of the rotor must not be reduced. The angular acceleration and deceleration of the rotor must not be affected such that aircraft control performance is reduced. Vertical thrust and its change over time is the basis for VTOL capability and aircraft control in hover. A reverse rotation of the rotor is typically not required. Due to the low rotor efficiency in reverse operation, one-directional forward operation is sufficient. The cooling of the powertrain that drives the rotor must not be negatively affected. Cooling of the high power and for aerodynamic reasons often closely housed vertical lift powertrain is challenging for most VTOL aircraft. Ideally a rotor storage system improves the cooling situation e.g. by opening cooling air inlets during the hover phase.

3) Impact on Aircraft Design: The structural integrity of the aircraft (e.g. a closed fuselage hull) shall as few as possible be affected by the rotor storage mechanism. The required space for the storage mechanism shall be minimal. A weakening of the aircraft structure must be counteracted by reinforcement material and thus adds mass to the mass sensitive VTOL vehicle. The same applies to an increased fuselage volume to fit a large rotor storage mechanism. The rotor storage mechanism shall be applicable to as much as possible fixedwing VTOL aircraft configurations. Ideally, a retrofit of the storage mechanism to existing fixed-wing VTOL 
aircraft shall be possible. A universal design makes the benefits of a rotor storage systems accessible for a maximum number of fixed-wing VTOL aircraft and keeps the necessary modifications for an integration low.

4) System Design: In general, the storage mechanism must be of low complexity, robust in its operation, of low maintenance effort and should be integrable as one distinct unit. As stated in the introduction, low system complexity and low maintenance effort are key reasons for the choice of the separated hover lift and cruise thrust concept. The installation of a complex rotor storage system contradicts that argumentation. Maintenance is facilitated if the system can be detached from the airframe as one unit to conveniently perform overhauls. The prop storage mechanism must be designed for the occurring loads and should not amplify them. Deformation due to the occurring loads must be minimal. Deformation under loads like rotor flapping moments or rotor unbalance can amplify its effect and negatively impact structural mass, controllability, maintenance intervals or durability of the whole aircraft.

\section{B. Morphological Design Room}

To follow a systematic though creativity-promoting approach, a morphological box (see Table 1) was filled with abstract solutions for certain functionalities.

\begin{tabular}{|c|c|c|c|c|c|c|c|c|}
\hline & \multicolumn{6}{|c|}{ Solution } \\
\hline & & & 1 & 2 & 3 & 4 & 5 & 6 \\
\hline \multirow{2}{*}{\multicolumn{2}{|c|}{ 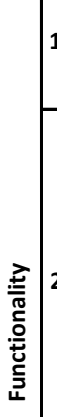 }} & principle of drag reduction & $\begin{array}{l}\text { rotor aligned } \\
\text { with airflow }\end{array}$ & $\begin{array}{l}\text { rotor stored in shape-fitted } \\
\text { recess }\end{array}$ & $\begin{array}{c}\text { rotor housed inside } \\
\text { doors }\end{array}$ & $\begin{array}{l}\text { rotor tilted } \\
\text { and folded }\end{array}$ & $\begin{array}{l}\text { rotor scissor } \\
\text { folding }\end{array}$ & \\
\hline & & $\begin{array}{l}\text { principle of rotor/motor } \\
\text { movement away from/to } \\
\text { fuselage }\end{array}$ & $\begin{array}{c}\text { no } \\
\text { movement }\end{array}$ & $\begin{array}{l}\text { threaded } \\
\text { shaft+bidirectional motor } \\
\text { rotation+friction/rotor } \\
\text { inertia }\end{array}$ & $\begin{array}{l}\text { aerodynamic lift of } \\
\text { rotor+spring+axially } \\
\text { moveable rotor along } \\
\text { shaft }\end{array}$ & $\begin{array}{c}\text { rotor blade } \\
\text { tilt (variable } \\
\text { blade } \\
\text { dihedral) }\end{array}$ & $\begin{array}{l}\text { motor+rotor } \\
\text { axially } \\
\text { moved by } \\
\text { actuator } \\
\text { (linear } \\
\text { guidance, } \\
\text { rectractable } \\
\text { pen } \\
\text { mechanism) }\end{array}$ & $\begin{array}{c}\text { motor+rotor } \\
\text { on lever arm } \\
\text { pivoted }\end{array}$ \\
\hline & 3 & $\begin{array}{l}\text { principle of blade azimuth } \\
\text { positioning }\end{array}$ & $\begin{array}{l}\text { motor } \\
\text { position } \\
\text { control }\end{array}$ & $\begin{array}{l}\text { rotor stop pin (flexible or } \\
\text { rigid but retractable) }\end{array}$ & & & & \\
\hline & 4 & $\begin{array}{l}\text { bidirectional shaft-rotor torque } \\
\text { transmission }\end{array}$ & fixed & friction/clamping & form fit & & & \\
\hline & 5 & $\begin{array}{c}\text { extracted/retracted position } \\
\text { sensing }\end{array}$ & none & limit switch & motor current sensing & & & \\
\hline
\end{tabular}

Table 1: Morphological box showing design solutions for inactive rotor drag reduction systems

The morphological box contains solutions implemented on existing fixed-wing VTOL designs ${ }^{2,3,4}$ and motor gliders which seek to reduce their cruise thrust producing propellers' drag during unpowered flight mode ${ }^{5,6}$. Additionally, own ideas and suitable non-aviation mechanisms are included.

Highlighted in orange is a solution combination that is this paper's reference drag reduction approach (see Figure $1 \mathrm{c} / \mathrm{d}$ ) as it is already employed by a variety of fixed-wing VTOL products due to its simplicity. The two blade rotor is positioned parallel to the fuselage axis by a position control functionality of the motor controller. Highlighted in blue is the solution combination developed in the context of this paper. For drag reduction, the two blade rotor is placed in a recess on the fuselage. The recess reflects the negative geometry of the rotors bottom side. Air flows over the homogenous surface composed of the fuselage surface and the rotor top side with low drag penalty and without flow separation. This approach allows to keep a structurally favorable, closed fuselage hull. The additional fuselage volume respectively surface is kept at a minimum. Off-the-shelf two-blade rotors can be used. A retrofit of a rotor recess on existing fuselages is even feasible. For the reason of a simple, rigid and lightweight motor attachment, solely the rotor is moved during the retraction and extraction. To drive the extension and retraction movement, the approach is to use the degrees of freedom of the electric motor itself as well as secondary forces like thrust, drag and inertial moments of the rotor. A separate actuation system whose failure would prohibit the rotor from operation is not required. Using the bidirectional rotation of the electric motor in combination with a threaded shaft allows to move the rotor from stored to extended position and back. An actuated rotor stop pin aligns the rotor with its recess during the retraction process. The stop pin is not able to hamper the rotor operation in case of a pin actuator failure. To transmit bidirectional 
torque between threaded shaft and rotor for fast rotor thrust variations, the rotor is clamped at its fully extended position. Simple limit switches sense the retracted position of the rotor. Cooling air inlets for the hover powertrain are covered by the retracted rotor and opened during the rotor extension process.

\section{Functional Testing and Drag Model Validation}

The suggested mechanism was implemented as a functional wind tunnel model (see Figure 2 and Figure 3 ) to tune and proof a reliable extension and retraction functionality as well as to determine the actual drag savings by the prop storage mechanism in comparison to the reference design.

\section{A. Functional Testing}

Functional testing focused on the mechanism principle as a whole and the fitness of the sub-design solutions. The

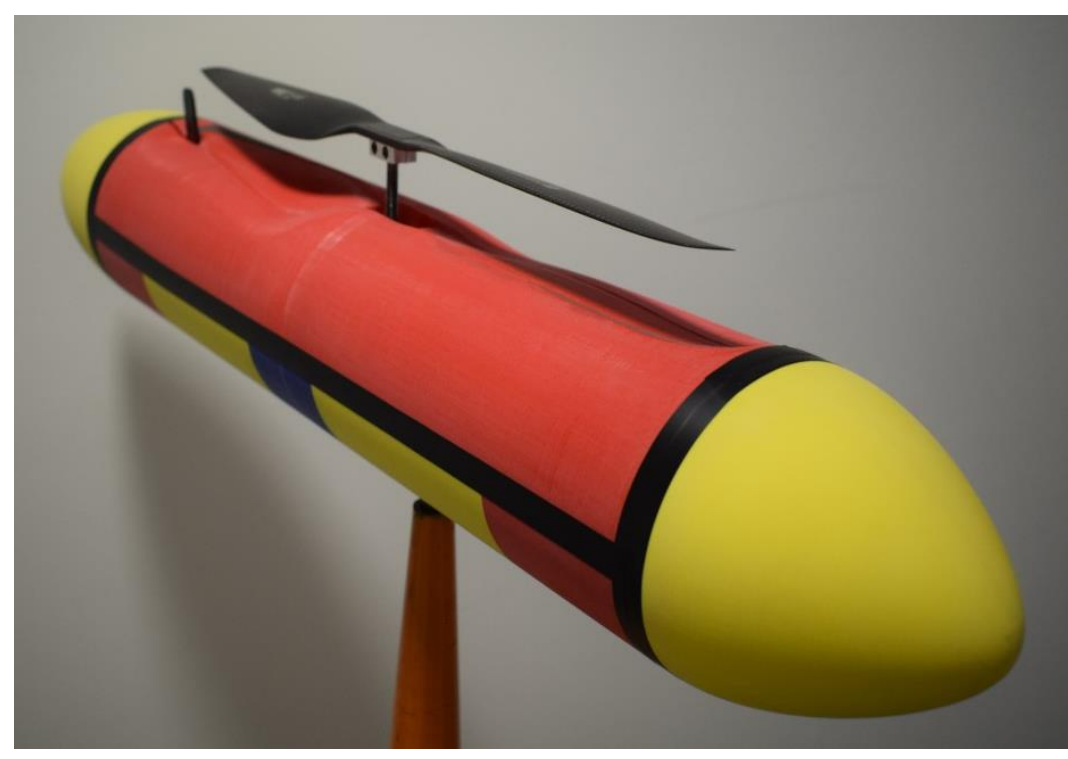

Figure 2: Wind tunnel model with rotor recess and extended rotor and stop pin

functionality, repeatability, robustness and wear of the mechanism shall be tuned and tested to approve its installation in a flying aircraft. The mass increase due to the mechanism in comparison to the reference design with a fixed rotor shaft of the same length and identical rotor, rotor-shaftconnector, electric motor and ESC components is 25.3 grams. The fuselage mass increase due to the rotor recess could not be tracked but is estimated to not exceed 5 grams. Considering the reference design's total mass (including rotor, rotor-shaftconnector, fixed shaft, electric motor, motor cables, ESC) of 248 grams, the rotor storage mechanism causes a relative mass increase of $12 \%$.

These tests were performed in the wind tunnel reflecting inflight airflow
conditions. Within an airspeed range of 0 to $30 \mathrm{~m} / \mathrm{s}$ a robust operation of the mechanism could be demonstrated. The time to extend the rotor to full operation is 3.6 $\mathrm{s}$ and $6.8 \mathrm{~s}$ to retract. Testing of the mechanism under maximum design airspeed condition and full thrust was Figure 3: Wind tunnel model in reference configuration (clean cylinder with rotor) successfully accomplished. Deformation or oscillation under this load condition stayed within tolerable limits. Conclusively, the rotor storage mechanism was approved for experimental on-aircraft inflight operation.

\section{B. Wind Tunnel Drag Saving Assessment}

To determine the drag saving coming from the rotor storage mechanism, to find out about related parameter sensitivities and to validate the drag estimation made in chapter C, 6-component force and moment measurements were recorded in the wind tunnel. The following parameters were varied:

- Model configuration: clean cylinder with and without rotor (see Figure 3), cylinder with rotor recess with rotor retracted and fully extended (see Figure 2) 
- Airspeed: 20 and $40 \mathrm{~m} / \mathrm{s}$, corresponding to dynamic pressures of 225 and $900 \mathrm{~Pa}$ or Reynolds numbers of $6.08 \cdot 10^{5}$ and $1.22 \cdot 10^{6}$ with $0.432 \mathrm{~m}$ rotor diameter as reference length

- Ange of attack: $0^{\circ}$ and $6^{\circ}$ relative to the cylinder axis

- Minimal vertical distance between clean cylinder and rotor blade trailing edge: 7 and $20 \mathrm{~mm}$

- $\quad$ Rotor blade azimuth angle: $0^{\circ}$ (aligned with cylinder axis) and $90^{\circ}$

The drag force measurements $D$ were normalized with the dynamic pressure $q$ to yield the drag area $c_{D} S$. It sums up the products of drag coefficient and corresponding area for all contributions to the overall drag.

$$
c_{D} S=\frac{D}{q}=c_{D, \text { prop }} S_{\text {prop }}+c_{D, \text { shaft }} S_{\text {shaft }}+\cdots
$$

Due to easier readability, the measurements were condensed to one mean value and standard deviations for further evaluation. Figure 4 shows the drag area difference of each measured configuration minus the drag area of the reference configuration.

$$
\Delta c_{D} S=c_{D} S-c_{D, r e f} S_{\text {ref }}
$$

Like before, the reference configuration features the rotor attached to a fixed shaft and aligned with the clean cylinder fuselage's axis (see Figure 3).

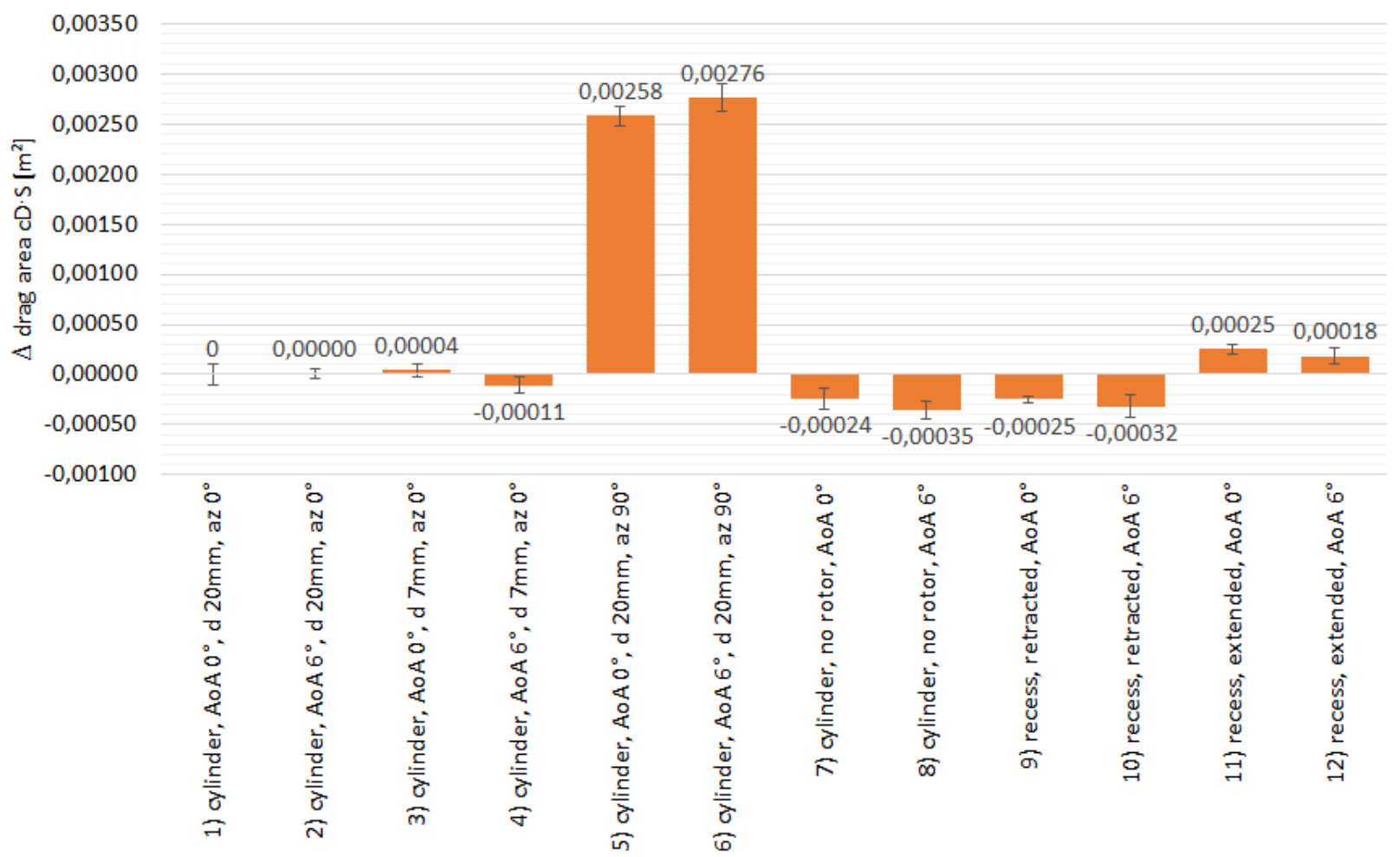

Figure 4: Drag areas for the tested configurations of inactive rotor drag reduction approaches

A significant drag difference of $0.0005 \mathrm{~m}^{2}$ for both angles of attack can be seen between extended and retracted prop storage mechanism (9 vs. 11 and 10 vs. 12). The configuration with rotor retracted in its recess shows similar drag as the clean cylinder configuration for both angles of attack ( 7 vs. 9 and 8 vs. 10). A drag saving of 0.00025 to $0.00032 \mathrm{~m}^{2}$ against the reference configuration is visible for the retracted prop storage mechanism (9 vs. 1 and $10 \mathrm{vs}$ 2). The extended rotor configuration clearly exhibits more drag than the reference configuration (11 vs. 1 and 12 vs. 2). That can be ascribed to the open recess surface featuring edges but as well to the wider threaded rotor shaft. The wind tunnel model of the reference configuration underrepresents the drag of a real aircraft installation as e.g. motor cooling is not implemented. Reduced drag for the $6^{\circ}$ angle of attack is implied for the configurations 3 vs. 4,7 vs. 8 , 9 vs. 10 and 11 vs. 12. As the drag reduction for higher angles of attack also happens for the configuration without rotor (7 vs. 8) a major contribution of the rotor to this effect is not suggested. Inconsistently, this effect is not visible for configurations 1 vs. 2 . The expectation that higher angles of attack cause additional induced drag on the rotor is disconfirmed. The likely explanation is the surface parallel airflow close to the fuselage body that keeps the effective angle of attack for the rotor blade close to zero. The influence of the distance fuselage-rotor on the drag force is 
minimal ( 1 vs. 3 ) for $0^{\circ}$ angle of attack. Drag is slightly increased when the rotor-fuselage distance is increased at $6^{\circ}$ angle of attack (4 vs. 2). The overall weak sensitivity on rotor-fuselage may suggest that the rotor is mostly outside the boundary layer for both distances. The drag of the longer shaft seems not graspable. The drag increase for the rotor perpendicular to the airflow is predominant (5 and 6). Here, the drag-relevant cross section is drastically increased, the blades produce lift and induced drag and might even operate in stall. An increase in angle of attack causes increased drag (5 vs. 6). Investigations with a wool string probe indicated vortices on the reference configuration behind the rotor-shaft-connector and the trailing edge constriction towards the blade root.

\section{Modelling of the Drag Saving}

During the conceptual design of the rotor storage mechanism, estimations on the drag savings were made. Under the assumption that a clean fuselage is equivalent in drag with a fuselage with rotor in its recess, the drag saving is caused by the omission of the rotor, rotor-to-shaft-connector and shaft. Like in chapter B, the overall drag area is summed up by the single component drag areas. The underlying assumption is that every component of this assembly is exposed to the same dynamic pressure outside the fuselage boundary layer. An estimated boundary layer thickness of the fuselage body at the downstream rotor tip of around $10 \mathrm{~mm}$ justifies this assumption (completely turbulent flow, fuselage begins with rotor tip) ${ }^{7}$.

Rotor drag is modelled as pure surface friction. This neglects pressure drag and induced drag. While pressure drag neglect is acceptable due to the low thickness of the rotor blades, induced drag can grow considerably due to the very low aspect ratio of the rotor blades when positioned flow parallel ${ }^{8}$. On the other hand, near-fuselage surface parallel flow limits the angle of attack of the rotor blade and therefore its lift and induced drag. This argumentation is not valid e.g. if the rotor blade extends beyond the fuselage front end. The flow over the rotor surface is assumed completely turbulent as the sharp-shaped blade tips likely trigger transition. Prandtl, von Karman, Schultz-Grunow and Schoenherr provide consistent surface friction coefficients for the dominant Reynolds number of $6 \cdot 10^{5}$ for turbulent flow. Drag coefficients for the rotor-to-shaft connector and the shaft can be found in Hoerner as well ${ }^{7}$. The respective reference surfaces are derived from the component geometries. Flow speed on the fuselage surface (outside the boundary layer) is accelerated and decelerated due to the change of the cross section area of the fuselage. Parts attached to the fuselage surface may therefore generate more drag than if exposed to a free flow field. Hoerner gives an idea on the increase of the drag coefficient due to this interference effect. Table 2 gives an overview on the resulting drag areas.

\begin{tabular}{|c|c|c|c|c|c|}
\hline & $\begin{array}{c}\text { drag/friction } \\
\text { coefficient [-] }\end{array}$ & $\begin{array}{c}\text { interference } \\
\text { factor [-] }\end{array}$ & $\begin{array}{c}\text { reference } \\
\text { area/wetted } \\
\text { surface }\left[\mathrm{m}^{2}\right]\end{array}$ & $\begin{array}{c}\text { drag area } \\
{\left[\mathrm{m}^{2}\right]}\end{array}$ & portion [-] \\
\hline rotor & 0,00509 & 1,325 & 0,025984 & 0,000175 & 0,431 \\
\hline connector & 0,9 & 1,325 & 0,000112 & 0,000134 & 0,328 \\
\hline shaft & 0,74 & 1,325 & 0,000100 & 0,000098 & 0,241 \\
\hline total & & & & 0,000407 & 1 \\
\hline
\end{tabular}

Table 2: Drag area break down

The estimated drag area difference of $0.0004 \mathrm{~m}^{2}$ ranges in the same magnitude as the measured values (configurations 'recess retracted': $0.00025 \mathrm{~m}^{2}$ and 'no rotor': $0.00024 \mathrm{~m}^{2}$ ), however overestimates it. Reconsidering the assumptions of a fully turbulent flow on the rotor blade surface to a partly laminar one and reducing the interference factor may be sensible corrections. As well, the section of the shaft within the boundary layer is exposed to less airspeed than modelled. The drag overestimation confirms the assumption that the rotor blades experience negligible angle of attack and hence produce no substantial induced drag.

\section{Overall Performance Benefit}

To evaluate the impact of an inactive rotor drag reduction system on the vehicle's overall mission performance, not only direct drag reduction but also mass and power consumption increase have to be considered. As a scale for the performance, cruise endurance is used. Adverse effects on other parts of the mission e.g. hover flight are considered negligible for the presented rotor storage system. Cruise endurance can be expressed by

$$
\begin{gathered}
t=\frac{E}{P}=\frac{E}{\frac{D v}{\eta}+P_{s y s}} \\
\text { with } D=D_{r e f}-D_{s y s}=\frac{\left(m+m_{s y s)} g\right.}{L / D}-\frac{\varrho}{2} v^{2} c_{D} S
\end{gathered}
$$




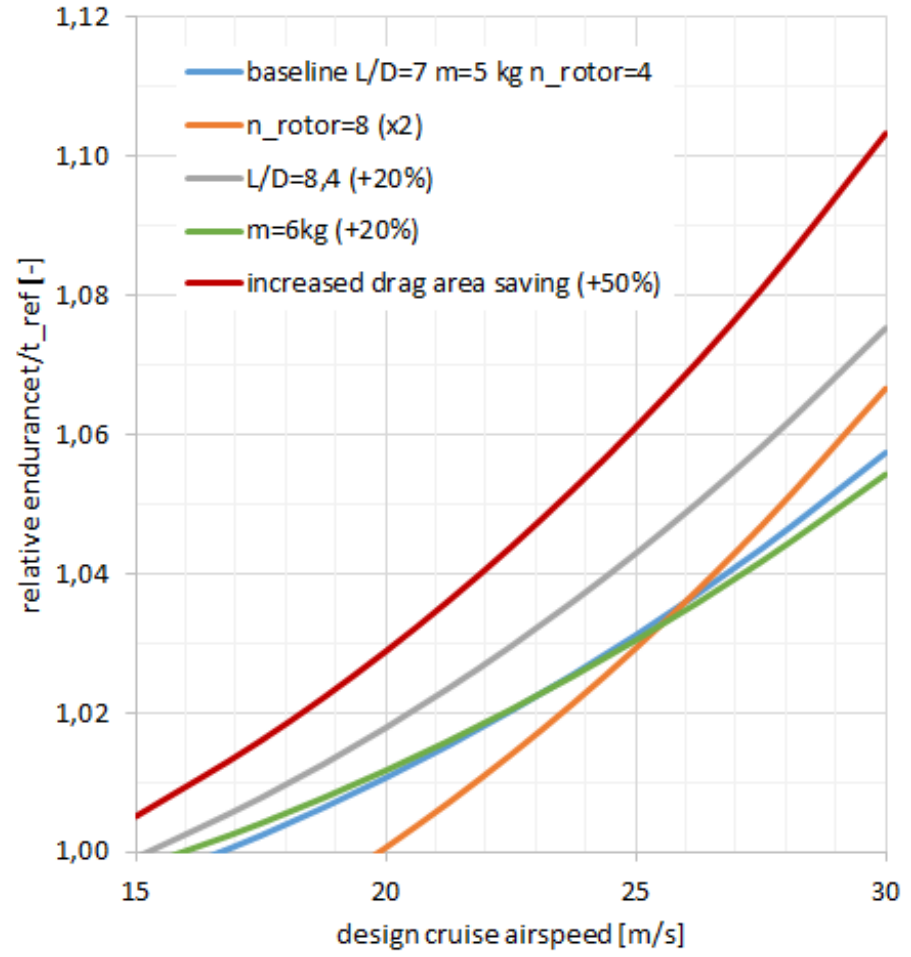

Figure 5: Relative endurance increase for the developed rotor storage system on an unmanned fixed-wing VTOL aircraft

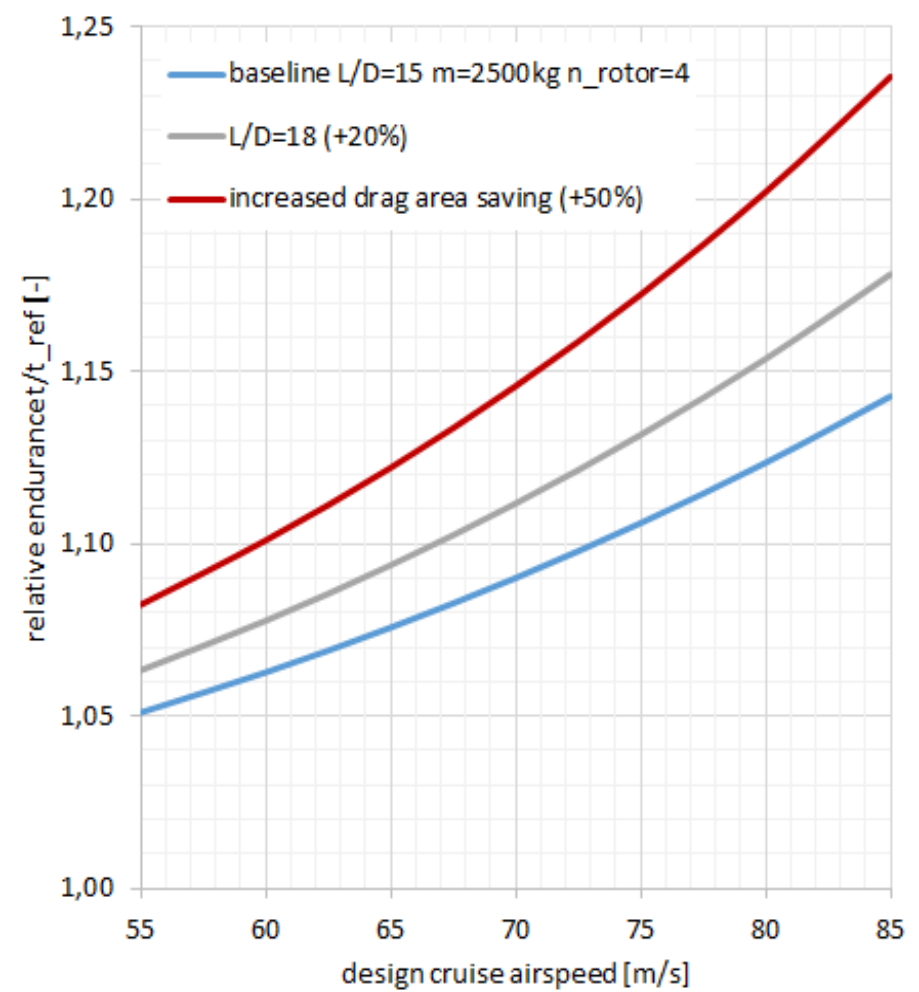

Figure 6: Relative endurance increase for the developed rotor storage system on a manned fixed-wing VTOL aircraft
An energy $E$ is available for cruise flight. Power consumption $P$ is composed of propulsive power and the rotor storage system's power $P_{\text {sys }}$. Aerodynamic drag $D$ consists of the reference aircraft's drag $D_{\text {ref }}$ and the rotor storage system's drag saving $D_{s y s}$. An exemplary comparison between the reference rotor alignment approach and the developed rotor storage system was first performed for an unmanned fixed-wing VTOL aircraft. A vehicle with four hover rotors, $5 \mathrm{~kg}$ aircraft mass $m$, a and glide ratio $L / D$ of 7 serves as baseline for the computations. The presented rotor storage mechanism with an additional mass $m_{s y s}$ of 30.5 grams and drag area saving $c_{D} S$ of $0.00025 \mathrm{~m}^{2}$ is applied to each of the rotors. System power is considered zero for both configurations. Available cruise energy for the mechanismequipped aircraft is assumed unchanged as well as glide ratio and cruise powertrain efficiency $\eta$. The negligibly small changes in required lift, induced drag and cruise thrust justify this simplification for the intended purpose. Figure 5 illustrates the relative endurance benefit $\frac{t}{t_{\text {ref }}}$ of the unmanned aircraft equipped with a rotor storage system over the reference aircraft with fuselage-aligned rotors for different design cruise airspeeds $v$. At an airspeed of $20 \mathrm{~m} / \mathrm{s}$ the endurance increase is $1.1 \%$, respectively $5.7 \%$ for $30 \mathrm{~m} / \mathrm{s}$ (see blue graph). The glide ratio for every design airspeed is assumed constant. As well the effect of a doubled number of rotors is depicted. Hereby, the drag area saving is calculated proportional to the rotor diameter. The rotor diameter derives by the constraint of a constant overall rotor disk loading. The additional mass per installed rotor storage mechanism is chosen independent of the rotor size with a constant value of $30.5 \mathrm{~g}$. Below 20 $\mathrm{m} / \mathrm{s}$ no benefit can be achieved by a rotor storage system. The additional mass disadvantages surpass the aerodynamic gains. The green graph represents the endurance benefit for a $20 \%$ heavier aircraft. An increase in glide ratio leads to a relative endurance improvement for all airspeeds (see grey graph). Using a 50\% increased value for the drag area saving (e.g. to account for the cooling drag penalty on the reference configuration), a relative endurance benefit depicted by the red graph can be yielded. Conclusively, the performance benefit of a rotor storage mechanism is not clear for the assumed

unmanned aircraft. Only vehicles with high cruise speed, high number of deactivated hover rotors and good aerodynamic performance can profit reasonably from a rotor storage system. The above evaluation on the endurance benefit was also performed for a manned electric fixed-wing VTOL dedicated for future urban air transport ${ }^{9}$. The 
underlying aircraft exhibits a total mass $m$ of $2500 \mathrm{~kg}$, a glide ratio $L / D$ of 15 and four hover rotors units. The additional mass of a rotor storage unit $m_{s y s}$ is assumed with $4 \mathrm{~kg}$. The drag saving is based on the above value but scaled to a typical rotor surface area and prevalent Reynolds number of around $1.7 \cdot 10^{7}$. Figure 6 presents the results. For the desired design airspeed of $67 \mathrm{~m} / \mathrm{s}$ a relative endurance benefit of $8 \%$ is predicted for a conservative drag saving assumption, $13.1 \%$ in an optimistic case. All in all, the size and speed regime of man-carrying fixed-wing VTOL is able to harvest the benefits of a rotor storage system to a significantly greater extent.

\section{Critical Review and Outlook}

As a starting point for the design of a system to reduce the drag of an inactive hover rotor on a fixed-wing VTOL aircraft, a list of performance, operability and safety related requirements was compiled. Applying a morphological box approach, possible solutions for the system's sub functionalities were developed and combined to a consistent overall concept. The main principle of the chosen concept is the retraction of the two blade rotor into a recess in the fuselage using the bidirectional rotation of a threaded rotor shaft. This concept was then transformed into a manufacturable design which is suitable for functional tests and drag measurements in a wind tunnel. Functional tests approved robust automatic retraction and extension sequences within the airspeed envelope of typical fixed-wing VTOL UAV aircraft. A maturity stage justifying the installation in an aircraft is reached. Real in-flight operation will further show weaknesses of storage system due to realistic airflow conditions, flight control and flight management system interaction, failure scenario handling and effects of wear over time. Drag measurements of the developed rotor storage system and a reference fixed rotor configuration were performed in the wind tunnel. A significant reduction in drag due to the retracted rotor could be proved. The gained data on drag savings was as well used to validate and suggest modifications to prior estimations based on empirical methods. Using the cruise endurance as a measure, the impact of the rotor storage system on overall aircraft performance was presented. The additional system mass is overcompensated by the drag saving and conclusively leads to a cruise endurance improvement for manned fixedwing VTOL configurations for urban air transport purposes. In the case of small unmanned fixed-wing VTOL aircraft, a rotor storage system seems only beneficial for high cruise speed and aerodynamically efficient designs with high number of hover rotors. It however must always be individually decided for the present aircraft design, concept of operations and economic requirements if an installation of a rotor storage system is sensible. A from-scratch design of the mechanism including rotor blade shape and electric motor will enable further robustness and performance improvements over the current off-the-shelf component usage and modification.

\section{Acknowledgement}

The activities on the rotor storage mechanism development were substantially supported by Thomas Blaim who contributed initial benefit estimations and concept drafts ${ }^{10}$, Sebastian Oberschwendtner who took care of the CAD and integration tasks and Andrei Buzica who supported the wind tunnel measurements at the Chair of Aerodynamics and Fluid Mechanics/Technical University of Munich.

\section{References}

1 UBER. (2016, October 27). Fast-Forwarding to a Future of On-Demand Urban Air Transportation. Retrieved from https://www.uber.com/elevate.pdf

2 Hirschberg, M. J. (1997, March/April). V/STOL: The First Half-Century. Vertiflite.

3 Poisson-Quinton, P. (1968). Introduction to V/STOL Aircraft Concepts and Categories. AGARDograph 126.

4 Anderson, S. ( 1981). Historical Overview of V/STOL Aircraft Technology. NASA Ames Research Center: NASA Technical Memorandum 81280.

5 Litherland, B. L., Patterson, M. D., Derlaga, J. M., \& Borer, N. K. (2017). A Method for Designing

Conforming Folding Propellers. Retrieved from https://ntrs.nasa.gov.

6 Pätzold, F. (2014). Results of Flight Performance Determination of the Lak-17a FES (S5-3117).

Braunschweig: Technische Universität Braunschweig, Institut für Flugführung.

7 Hoerner, S. F. (1965). Fluid-Dynamic Drag. Bakersfield, CA: Hoerner Fluid Dynamics.

8 Ortiz, X., Rival, D., \& Wood, D. (2015). Forces and Moments on Flat Plates of Small Aspect Ratio with Application to PV Wind Loads and Small Wind Turbine Blades. Energies.

9 UBER. (2018, May 14). eCRM-003. Retrieved from https://www.uber.com/info/elevate/ecrm/

10 Blaim, T. (2018). Entwicklung eines Mechanismus zur Reduktion des aerodynamischen Widerstands der inaktiven Propeller am 5TOL UAV. Munich: Institute of Aircraft Design/Technical University of Munich. 